\title{
Differences in the erodibility and hydrological response of slope forming materials from an iron ore mine, West Africa
}

\author{
S.J. Campbell National Soil Resources Institute, Cranfield University, UK \\ R.W. Simmons National Soil Resources Institute, Cranfield University, UK \\ R.J. Rickson National Soil Resources Institute, Cranfield University, UK
}

\begin{abstract}
Published data are sparse on the erodibility and hydrological response of slope-forming materials (SFMs) commonly found at iron ore mine sites, such as ore, soil and waste rock. This research critically evaluates the erodibility and hydrological response of 10 SFMs derived from an iron ore mine in West Africa. The SFMs were tested under both field-capacity and air-dry antecedent moisture conditions, indicative of soil moisture status both before and during the onset of monsoonal rains. The total volumes of runoff and of leachate generated by each of the SFMs when subjected to simulated rainfall were determined. The sediment load (TSL) of the runoff and leachate were also measured. Three replicates of each SFM at each antecedent moisture condition were prepared in $0.5 \times 0.25 \times 0.15 \mathrm{~m}$ erosion trays set on a 10 degree gradient. Each replicate was subjected to a design-storm of $100 \mathrm{~mm} \mathrm{hr}^{-1}$ for 30 minutes duration. Statistical differences in the measured erodibility (material eroded) and hydrological response were evaluated using One-way ANOVA with Post-hoc Fisher LSD, using STATISTICA software. Further, multiple-regression analysis (MRA) was used to correlate the physical and chemical properties of the SFMs with their erodibility and hydrological response under the design storm event. Properties included in the MRA were organic carbon, cation exchange capacity, $\mathrm{pH}, E C$, density, particle size and dry-aggregate distribution, mineralogy and magnetic susceptibility. The weathered phyllite (PHY-WEA) waste-rock and colluvial soil (SRE) gave significantly higher runoff volumes when compared with all other SFMs. In contrast, with the exception of PHY-WEA and SRE, at both antecedent moisture conditions, all other SFMs gave significantly higher leachate as compared with runoff volumes. PHY-WEA also produced significantly higher TSL when compared with all other treatments, with mean values of $47.8 \mathrm{~g}$ and $165 \mathrm{~g}$ per erosion tray, respectively. This equates to TSC concentrations of 14.3 and $26.2 \mathrm{~g} \mathrm{l}^{-1}$, which are well in excess of the mine water quality target of $<0.05 \mathrm{~g} \mathrm{l}^{-1}$. The results of this research provide a greater understanding of the erodibility and hydrological response of ore, soil and waste rock SFMs. The research findings have important implications for the management and design of ore stock piles, waste rock dumps, sedimentation ponds and water discharge structures at mine sites. The MRA results demonstrate that variables including magnetic susceptibility, bulk mineralogy and dry aggregate distribution, which are not commonly assessed in erosion studies, are important parameters governing the erodibility and hydrological response of SFMs.
\end{abstract}

\section{$1 \quad$ Introduction}

Modern mining operations generate significant quantities of soil, waste rock and ore and are often associated with unconsolidated waste rock landscapes with steep slopes that are highly erodible (So et al., 2002; Williams, 2001). Such unconsolidated slope-forming materials (SFMs) are particularly sensitive to degradation by accelerated erosion (Andres and Jorba, 2000; Loch, 2000; Moreno-de las Heras et al., 2009) due to low infiltration and high erodibility. However, published data are sparse on the erodibility and hydrological response of SFMs generated by mining activities, particularly those commonly found at iron ore mine sites, such as ferralitic soils waste rock and iron ores. Understanding and quantifying the comparative erodibility and hydrological response of SFMs has important implications for the management and design of ore stock piles, waste rock dumps, sedimentation ponds and water discharge structures at mine sites. This research was undertaken to address this knowledge gap. 


\section{Experimental design}

\subsubsection{Characterisation of slope-forming materials}

Ten SFMs derived from an iron ore mine in West Africa, consisting of ore, waste rock and soil, were included in the study: lithosol (LITH), colluvisol (SRE), ferrosol (FER), alluvisol (ALL), rubbly drift (RD), weathered phyllite (PHY-WEA), haul road surface (HRS), weathered mineralised material (New-WEA and COMB-WEA) and friable mineralised material (FMM). Following air-drying and thorough mixing, these SFMs were characterised for $\mathrm{pH}$ and EC, (Thomas, 1996); Rhoades, 1996); for organic carbon (Nelson and Sommers, 1996); for exchangeable $\mathrm{Ca}, \mathrm{Na}, \mathrm{Mg}$, $\mathrm{K}$ and cation exchange capacity (CEC) (ammonium acetate extraction; MAFF, 1986); for dry aggregate distribution (Smith and Mullins, 2001; Nimmo and Perkins, 2002); and for particle size distribution (PSD) (BSI, 2010). Few research papers compare the magnetic properties of soil and non-soil SFMs and assess the linkages between magnetic susceptibility (MS) and erodibility (Rhoton et al., 1998). The SFMs in this study have originated from a site known to be rich in iron minerals. Consequently, in order to clarify the role of MS in the comparative erodibility of the SFMs included in this study, MS was determined following Dearing (1999). In addition, bulk mineralogy was assessed by following Omotoso et al. (2006) using X-ray powder diffraction (XRPD). Samples were wet ground in ethanol. The XRPD pattern was recorded from $2-75^{\circ} 2 \theta$ using cobalt Ka radiation. Quantitative analysis was undertaken by a normalised full pattern reference intensity ratio method with a $95 \%$ confidence level.

\subsubsection{Design storm event}

The design storm for the experimental programme was specified as the 1:20 year return period event for the mine location of $100 \mathrm{~mm} \mathrm{hr}^{-1}$ intensity for 30 minutes duration. This was based on observations obtained from intensity, duration and frequency curves created from rainfall data from the study area. A pressurised rainfall simulator was subsequently calibrated to the desired storm conditions. To obtain the specified rainfall intensity and kinetic energy (K.E.), a full cone nozzle (Lechler number 460.886.17) was set at 0.85 bar pressure with the simulator's boom arm set at $2.4 \mathrm{~m}$ above the ground level. The maximum rain drop size was $2.9 \mathrm{~mm}$ and median drop size (D50) across the target area was $1.34 \mathrm{~mm}$ ( $\pm 0.03 \mathrm{SE}$ ). Mean temporal and spatial storm K.E. was recorded as $46.0 \mathrm{~J} \mathrm{~m}^{2}( \pm 3.60 \mathrm{SE})$, indicative of high-intensity tropical rainfall (Loch, 1994; Lal, 1998).

\subsubsection{Indicators of erodibility and hydrological response to simulated rainfall}

Three test replicates of each SFM were placed into $0.5 \mathrm{~m}(\mathrm{I}) \times 0.25 \mathrm{~m}(\mathrm{w}) \times 0.15 \mathrm{~m}(\mathrm{~d})$ erosion trays. Erosion trays were subsequently compacted using a flat $0.25 \times 0.5 \mathrm{~m}$ rectangular metal plate to achieve a level surface and for each SFM, a replicable bulk density. The erosion trays were then set at a uniform slope of $10^{\circ}$ prior to being randomly subjected to the design storm event. Each erosion tray had two separate hoses connected for the collection of surface runoff and leachate. The comparative erodibility and hydrological response of the SFMs was assessed through the determination of total runoff volume $(\mathrm{ml})$, runoff rate $(\mathrm{ml}$ $\mathrm{min}^{-1}$ ), runoff total sediment load (TSL), leachate volume $(\mathrm{ml})$ and leachate TSL (g). An assessment of SFM erodibility was carried out under both air-dry antecedent moisture conditions $\left(A D_{\text {amc }}\right)$ and field capacity antecedent moisture conditions ( $F C_{a m c}$ ) in order to replicate field conditions at the mine location during the wet and dry season. However, for brevity, only the results of the $A D_{a m c}$ are reported here. Statistical differences in the data were evaluated using One-way ANOVA followed by Post-hoc Fisher LSD analysis, using STATISTICA software (v.10). Principal component analysis (PCA) using STATISTICA (v.10) was undertaken to determine if it was statistically expedient to separate the soil and non-soil data set prior to undertaking stepwise linear multiple regression analysis (MRA). MRA was undertaken to identify key SFM properties that dictate the hydrological response and erodibility of the SFMs tested. 


\section{$3 \quad$ Results}

\subsection{Characterisation of slope-forming materials}

The results indicate that the bulk density of the soils is, as expected, significantly lower than the non-soil SFMs, with mean ( $n=3$ ) values for the soils and non-soil SFMs ranging between 0.759 and $0.906 \mathrm{Mg} \mathrm{m}^{3}$ and between 1.029 and $2.604 \mathrm{Mg} \mathrm{m}^{3}$, respectively (Table 1). All of the 10 SFMs are considered acidic, with $\mathrm{pH}$ values ranging from 4.76 to 6.39. Further, soils LITH $(\mathrm{pH} \mathrm{5.1),} \mathrm{FER}(\mathrm{pH} \mathrm{4.76)}$ and ALL (pH 4.9) are significantly more acidic than all other SFMs. SFM EC ranges from 1,443 to $2,040 \mu \mathrm{S} \mathrm{cm}^{-1}$. Soil SFMs had, as expected, significantly higher organic carbon values (\% weight per weight; $\% \mathrm{w} / \mathrm{w}$ ) compared with the nonsoil SFMs. Specifically, mean organic carbon values for the soils are in the order SRE, LITH, FER and ALL, with values of $10.3,6.5,4.0$ and $3.46 \%$, respectively. In contrast, all non-soil SFMs were associated with organic carbon values of $<0.57 \%$.

All SFMs are associated with trace levels of Exch-K. The Exch-Ca values for the non-soils and soils are not represented by distinctly different populations. The highest concentrations of Exch-Ca are associated with the soils SRE and LITH, and the non-soil RD with values of $11.6,6.53$ and 8.20 meq $100 \mathrm{~g}^{-1}$ respectively. The remaining SFMs have Exch-Ca concentrations $<4.0$ meq $100 \mathrm{~g}^{-1}$. The soils ALL, FER and SRE have the highest Exch-Mg values, ranging between 1.31 and 2.21 meq $100 \mathrm{~g}^{-1}$. Further, as with the Exch-K results, non-soil RD and soil LITH are associated with statistically similar Exch-Mg values of 0.37 and 0.38 meq $100 \mathrm{~g}^{-1}$ respectively. All other non-soil SFMs are associated with Exch-Mg concentrations $<0.11$ meq $100 \mathrm{~g}^{-1}$. All SFMs are associated with trace levels of Exch-Na ranging from $0.02-0.10$ meq $100 \mathrm{~g}^{-1}$. Few research papers compare the magnetic properties of soils and non-soils and assess the linkages between magnetic susceptibility (MS) and erodibility (Rhoton et al., 1998). Significant differences in MS were in the order SRE $>$ LITH $>$ RD $=$ NEW-WEA $>$ FER $=$ HRS $=$ COMB-WEA $=$ FMM $=$ PHY-WEA $>$ FER $=$ FMM $>$ ALL (Table 1). The results show no statistical distinction between the soils and non-soil SFMs with regard to MS.

The mineralogical composition of the SFMs are summarised in Table 2. It is important to note that only single mineralogical results were obtained for each SFM and so they could not be statistically analysed for variance. The X-ray powder diffraction (XRD) method used has been extensively validated (Omotoso et al., 2006), and the mineralogical composition of the same SFM is highly likely to give identical XRD patterns (Stephen Hillier, The James Hutton Institute, pers. comm., February 2012). The soils have higher quartz content than the non-soils. Soils ALL, FER and SRE are dominated by quartz and kaolinite with composition values of $48.8,48.0$ and 48.6 and of $35,28.2$ and 35 (\% w/w), respectively. In contrast, LITH is associated with a more diverse mineralogy (\% $w / w)$, including quartz (22.1), kaolinite (14.8), gibbsite (9.7), goethite (14.9) and hematite (7.5). With the exception of PHY-WEA, non-soils are dominated by hematite and/or goethite with COMB-WEA and FMM associated with 74.5 and $86.8 \% \mathrm{w} / \mathrm{w}$ hematite, respectively. Non-soils RD and HRS are dominated by hematite $(26.3$ and $56.2 \% \mathrm{w} / \mathrm{w})$ and goethite $(51.7$ and $24.1 \% \mathrm{w} / \mathrm{w})$. PHYWEA is dominated by muscovite and kaolinite with values of 50.8 and $19.2 \% \mathrm{w} / \mathrm{w}$ respectively. In all SFMs, anatase and rutile are found in trace amounts.

SFM dry aggregate distribution (DAD) was assessed using 12 size fractions ranging from $>37.5 \mathrm{~mm}$ to $<53 \mu \mathrm{m}$. The DAD results represent non-dispersed aggregate distribution. The detailed data set was necessary to assess which aggregate size classes are important factors in the runoff, leachate and erosion results using multiple regression analysis. Soils LITH and SRE show DAD aggregate size $250 \mu \mathrm{m}-2 \mathrm{~mm}$ to be the dominate size class, and for ALL and FER the dominant DAD size class is $0.5 \mathrm{~mm}-19 \mathrm{~mm}$. DAD aggregates sized $5.6-19 \mathrm{~mm}$ is the dominate size class in the non-soils, with proportions ranging between 17.7 and $35.3 \% \mathrm{w} / \mathrm{w}$. HRS and FMM have significantly higher 63-125 $\mu \mathrm{m}$ sized aggregates at 8.86 and $8.59 \% \mathrm{w} / \mathrm{w}$ respectively. FMM has significantly the highest amount of $<53 \mu \mathrm{m}$ aggregates of all the SFMs at 10.3\%. Like other non-soils, PHY-WEA has high amounts of $5.6-19 \mathrm{~mm}$ aggregates $(17.7 \%)$ and also significantly high amounts of aggregates $125 \mu \mathrm{m}-1 \mathrm{~mm}(46 \%)$. For brevity, the full DAD dataset is not shown. 
Table 1 Physical and chemical characteristics of SFMs

\begin{tabular}{|c|c|c|c|c|c|c|c|c|c|c|c|}
\hline \multirow[b]{2}{*}{ SFM } & \multirow[b]{2}{*}{ Type of SFM } & \multirow[b]{2}{*}{$\begin{array}{c}\text { Bulk } \\
\text { Density } \\
\left(\mathrm{Mg} \mathrm{m}^{-3}\right)\end{array}$} & \multirow[b]{2}{*}{ pH } & \multirow[b]{2}{*}{$\begin{array}{c}E C \\
\left(\mu \mathrm{Ccm}^{-1}\right)\end{array}$} & \multirow[b]{2}{*}{$\begin{array}{c}\text { Organic } \\
\text { Carbon } \\
(\% \mathrm{w} / w)\end{array}$} & \multicolumn{6}{|c|}{ Exchangeable Cations (meq $100 \mathrm{~g}^{-1}$ ) } \\
\hline & & & & & & $\begin{array}{c}\text { Magnetic } \\
\text { Susceptibility } \\
\left(\mathrm{m}^{3} \mathrm{~kg}^{-1}\right)\end{array}$ & $\mathrm{Ca}$ & Mg & K & $\mathrm{Na}$ & $\begin{array}{c}\text { CEC } \\
\left.\text { (meq } 100 \mathrm{~g}^{-1}\right)\end{array}$ \\
\hline LITH & Soil & $0.811_{\mathrm{ab}}$ & $5.10_{\mathrm{e}}$ & $1454_{c}$ & $6.50_{f}$ & $174.8_{d}$ & $6.53_{d}$ & $0.38_{c}$ & $0.29 \mathrm{c}$ & $0.04_{c}$ & $24.2 \mathrm{c}$ \\
\hline ALL & Soil & $0.869_{b c}$ & $4.90_{c}$ & $1768_{a b}$ & $3.46_{d}$ & $-0.2 b$ & $2.96_{b c}$ & $1.31_{d}$ & $0.17 b$ & $0.10_{f}$ & $18.0_{b}$ \\
\hline FER & Soil & $0.906_{c}$ & $4.76_{c}$ & $1769_{a b}$ & $4.00_{\mathrm{e}}$ & $29 a$ & $2.56_{a b c}$ & $1.48_{\mathrm{e}}$ & $0.44_{d}$ & $0.033_{\mathrm{ac}}$ & $18.3_{b}$ \\
\hline SRE & Soil & $0.759 a$ & $5.40_{\mathrm{a}}$ & $1722_{a}$ & $10.3_{\mathrm{g}}$ & $438.3_{e}$ & $11.6_{\mathrm{e}}$ & $2.21_{f}$ & $0.63_{\mathrm{e}}$ & $0.04_{c}$ & $32.3_{d}$ \\
\hline $\mathrm{RD}$ & Non-soil & $1.36_{\mathrm{e}}$ & $5.63_{b}$ & $1443_{c}$ & $0.57_{c}$ & $60.8_{c}$ & $8.20_{d}$ & $0.37_{c}$ & $0.20_{b}$ & $0.026_{a b}$ & $15.5_{b}$ \\
\hline PHY-WEA & Non-soil & $1.029_{d}$ & $5.63_{b}$ & $1680 a$ & $0.17_{\mathrm{ab}}$ & $27.2 \mathrm{a}$ & $1.16_{\mathrm{ab}}$ & $0.11_{b}$ & $0.05 a$ & $0.026_{a b}$ & $2.43_{a}$ \\
\hline NEW-WEA & Non-soil & $2.098 \mathrm{~g}$ & $5.50_{a b}$ & $1776_{a b}$ & $0.23_{b}$ & $61.7_{c}$ & $1.13_{\mathrm{ab}}$ & $0.05_{a b}$ & $0.02 a$ & $0.03_{a}$ & $2.43_{a}$ \\
\hline COMB-WEA & Non-soil & $2.46_{i}$ & $5.99 \mathrm{~d}$ & $2040_{d}$ & $0.13_{a b}$ & $31.4 a$ & $1.10_{\mathrm{ab}}$ & $0.068_{\mathrm{ab}}$ & $0.01_{a}$ & $0.05 e$ & $1.70_{a}$ \\
\hline HRS & Non-soil & $1.76_{f}$ & $6.06_{d}$ & $1480_{c}$ & $0.47_{c}$ & $33.5_{a}$ & $3.86_{c}$ & $0.08_{a b}$ & $0.02 a$ & $0.02_{b d}$ & $5.23_{a}$ \\
\hline FMM & Non-soil & $2.604_{j}$ & $5.43 a$ & $1830_{b}$ & $<0.001_{\mathrm{a}}$ & $10.7_{\mathrm{ab}}$ & $0.77 a$ & $0.03_{a}$ & $0.01_{a}$ & $0.03_{a}$ & $1.93_{a}$ \\
\hline
\end{tabular}

Within the same column, values not followed by the same letter are significantly different at $p<0.05$ as determined by One-way ANOVA and post-hoc Fisher LSD analysis. 
Table 2 Bulk mineralogical composition of the SFMs (\% w/w)

\begin{tabular}{|c|c|c|c|c|c|c|c|c|c|c|c|}
\hline SFM & Quartz & Plagioclase & Hematite & Goethite & Magnetite & Maghemite & Anatase & Rutile & Gibbsite & Muscovite & Kaolinite \\
\hline LITH & 22.1 & ND & 7.5 & 14.9 & ND & 8.5 & 0.7 & 0.5 & 9.7 & ND & 14.8 \\
\hline ALL & 48.8 & 1.0 & ND & 4.9 & ND & 1.1 & 0.2 & 0.7 & 0.4 & ND & 35.0 \\
\hline FER & 48.0 & 0.5 & 1.0 & 6.2 & 1.3 & 1.0 & 0.4 & 0.3 & 4.5 & ND & 28.2 \\
\hline SRE & 48.6 & 1.0 & ND & 4.9 & ND & 1.1 & 0.2 & 0.7 & 0.4 & ND & 35.0 \\
\hline $\mathrm{RD}$ & 1.7 & ND & 26.3 & 51.7 & ND & ND & 0.3 & ND & 15.0 & ND & 5.0 \\
\hline PHY-WEA & 2.8 & ND & 7.3 & 13.7 & ND & 2.2 & ND & 0.3 & 3.7 & 50.8 & 19.2 \\
\hline COMB-WEA & 1.4 & ND & 75.4 & 11.8 & 6.1 & ND & 0.1 & 0.1 & 4.7 & ND & 1.3 \\
\hline HRS & 4.8 & ND & 56.2 & 24.1 & ND & 0.6 & 0.1 & 0.1 & 8.6 & ND & 5.5 \\
\hline FMM & 4.1 & ND & 86.8 & 0.8 & 3.0 & ND & ND & 0.1 & 3.5 & ND & 1.6 \\
\hline
\end{tabular}

Organic carbon results have been omitted as these were obtained in separate analysis reported in Table 1. Note only single mineralogical results was obtained for each SFM and so could not be statistically analysed for variance. The XRPD method used has been extensively validated (Omotoso et al., 2006) and mineralogical composition of the same SFM is very likely to give identical XRD patters (Stephen Hillier, pers. comm., February 2012). Due to insufficient material available no results are presented for NEW-WEA. ND = non-detectable. 
The results of the 5-fraction particle size distribution analysis indicate significant differences in the PSDs of the soil and non-soil SFMs (Table 3). Soils LITH and SRE are dominated by the silt- $(50$ and $51 \% \mathrm{w} / \mathrm{w}$ ) and clay- ( 30 and $24 \% \mathrm{w} / \mathrm{w}$ ) sized fractions. In contrast, ALL is dominated by the silt/fine sand $(37.9 \%)$ and claysized fractions (37.6\%) and FER by the clay-sized (42.6\%) and medium-sand-sized fractions (25\%). With the exception of PHY-WEA, the non-soils RD, WEA, NEW-WEA, COMB-WEA, HRS and FMM are dominated by the sand-sized fractions, with values of $61.0,85.6,64.2,87.0,74.9$ and $78.2 \%(w / w)$, respectively. In contrast, PHY-WEA is dominated by silt- $(65.6 \%)$ and clay-sized fractions (15.6\%).

\section{Table 3 SFM particle size distribution $(\% \mathrm{w} / \mathrm{w})$}

\begin{tabular}{|c|c|c|c|c|c|}
\hline SFM & $\begin{array}{l}\text { Coarse Sand } \\
2-0.63 \mathrm{~mm}\end{array}$ & $\begin{array}{l}\text { Medium Sand } \\
0.63-0.212 \mathrm{~mm}\end{array}$ & $\begin{array}{l}\text { Fine Sand } \\
0.212-0.063 \mathrm{~mm} 0.063\end{array}$ & $\begin{array}{l}\text { Silt } \\
-0.002 \mathrm{~mm}\end{array}$ & Clay $<0.002 \mathrm{~mm}$ \\
\hline LITH & $8.00_{a}$ & $6.33_{a}$ & $5.00_{a b}$ & $50.0_{f}$ & $30.6_{f}$ \\
\hline ALL & $6.33 a$ & $18.0_{b c}$ & $13.6_{e}$ & $24.3_{\mathrm{e}}$ & $37.6 \mathrm{~g}$ \\
\hline FER & $7.66_{a}$ & $25.0_{\mathrm{e}}$ & $11.6_{\mathrm{de}}$ & $13.0_{b c}$ & $42.6_{h}$ \\
\hline SRE & $18.0_{b}$ & $4.66 \mathrm{a}$ & $2.33_{a}$ & $51.0_{f}$ & $24.0_{e}$ \\
\hline $\mathrm{RD}$ & $37.0_{d}$ & $15.0_{b}$ & $9.00_{c d}$ & $20.3_{d}$ & $18.6_{d}$ \\
\hline PHY-WEA & $6.33_{a}$ & $4.66 \mathrm{a}$ & $7.66_{b c}$ & $65.6 \mathrm{~g}$ & $15.6_{c}$ \\
\hline NEW-WEA & $16.0_{b}$ & $21.6_{d}$ & $26.6_{f}$ & $26.3 \mathrm{e}$ & $9.33_{b}$ \\
\hline COMB-WEA & $30.0_{\mathrm{c}}$ & $31.0_{\mathrm{f}}$ & $26.0_{\mathrm{f}}$ & $10.0_{a}$ & $3.00_{a}$ \\
\hline HRS & $27.0_{c}$ & $27.6_{e}$ & $20.3_{\mathrm{g}}$ & $14.3_{c}$ & $10.6_{b}$ \\
\hline FMM & $17.6_{b}$ & $20.6_{c d}$ & $40.0_{i}$ & $18.3_{d}$ & $3.33_{a}$ \\
\hline
\end{tabular}

Within the same column, values not followed by the same letter are significantly different at $p<0.05$ as determined by One-way ANOVA and posthoc Fisher LSD analysis.

\subsection{Comparative erodibility and hydrological response of SFMs}

\subsubsection{Total runoff and leachate volume}

One-way ANOVA and post-hoc Fisher LSD analysis demonstrates that total runoff volume $(\mathrm{ml})$ was in the order HRS=PHY-WEA=SRE > COMB-WEA=PHY-WEA=SRE > COMB-WEA=SRE=LITH > ALL=FER=RD=FMM. HRS, PHY-WEA and SRE are associated with runoff volumes orders of magnitudes higher than all other treatments, with values of $4,249,3,333$ and $2,520 \mathrm{ml}$, respectively (Figure 1 ). The results also indicate that the hydrological response of soils LITH, ALL and FER is the generation of leachate with runoff and leachate values of $617,143,267 \mathrm{ml}$ and 3,884, 5,888 and 5,456 ml, respectively. A similar trend is observed for nonsoils RD, NEW-WEA, COMB-WEA and FMM (Figure 1). In contrast the hydrological response of PHY-WEA and HRS is the preferential generation of runoff. Soil SRE is the only SFM that is associated with the equitable generation of leachate and runoff. 


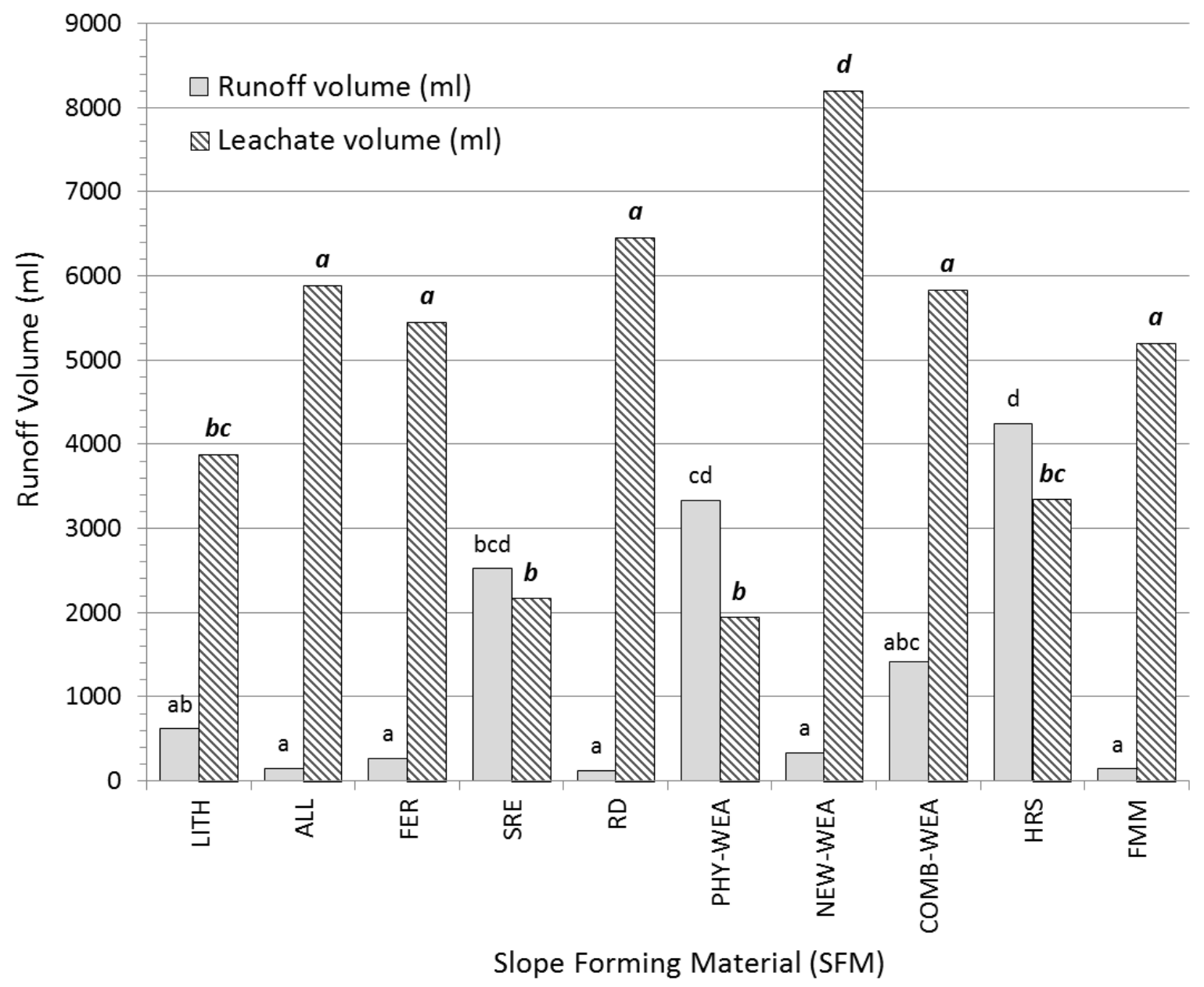

Figure 1 SFM runoff and leachate volumes $(\mathrm{ml})$; note: for the runoff and leachate results, bars associated with the same letter are not significantly different at $p<0.05$ as determined by One-way ANOVA and post-hoc Fisher LSD analysis

\subsubsection{Runoff and leachate TSL}

The preferential generation of runoff associated with PHY-WEA and HRS and balanced runoff/leachate volumes associated with SRE predisposes these SFMs to the entrainment and off-site transport of surface material detached by raindrop impacts. This is manifested by significantly higher runoff TSL values as compared with all other treatments (Figure 2). Specifically, the most erodible SFM is PHY-WEA, with a mean runoff TSL value of $47.8 \mathrm{~g}$. In contrast, with the exception of SRE $(10.2 \mathrm{~g})$ and HRS $(12.2 \mathrm{~g})$, all other SFMs are associated with runoff TSL values of $<2.5 \mathrm{~g}$, with ALL, FER, RD, NEW-WEA and FMM associated with runoff TSL values of $<1.0 \mathrm{~g}$. The preferential generation of leachate and low-runoff TSL values associated with LITH, All and FER suggest that these soils remain stable under the design storm event with limited aggregate breakdown and hence insufficient detached material to facilitate structural seal formation and to initiate runoff generation. In contrast, the preferential generation of leachate and low-runoff TSL values associated with RD, NEW-WEA, COMB-WEA and FMM are primarily a function of their high porosity resulting from the dominance of aggregates (DAD) ranging from 2.36 to $37.0 \mathrm{~mm}$. Further, for soils LITH and ALL and non-soil FMM, no significant difference was observed between leachate and runoff TSL. In contrast, soil FER and non-soils RD, NEW-WEA and COMB-WEA are associated with significantly higher leachate as compared with runoff TSL (Figure 3). The contrasting hydrological response and comparative dominance of erosion via runoff or leachate has significant implications for the placement and design of waste-rock dumps and associated runoff management structures. 


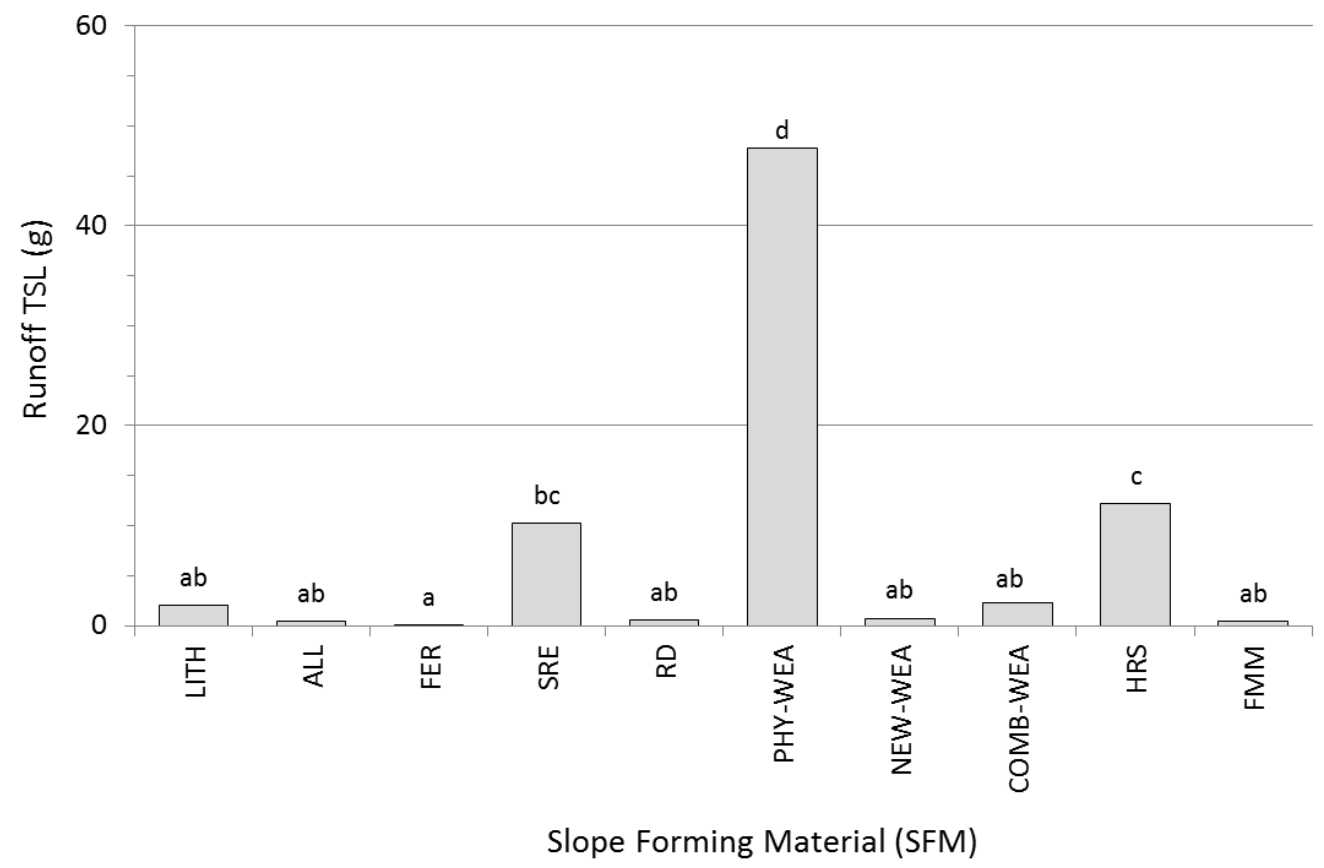

Figure 2 SFM runoff TSL (g); note: bars associated with the same letter are not significantly different at $p<0.05$ as determined by One-way ANOVA and post-hoc Fisher LSD analysis

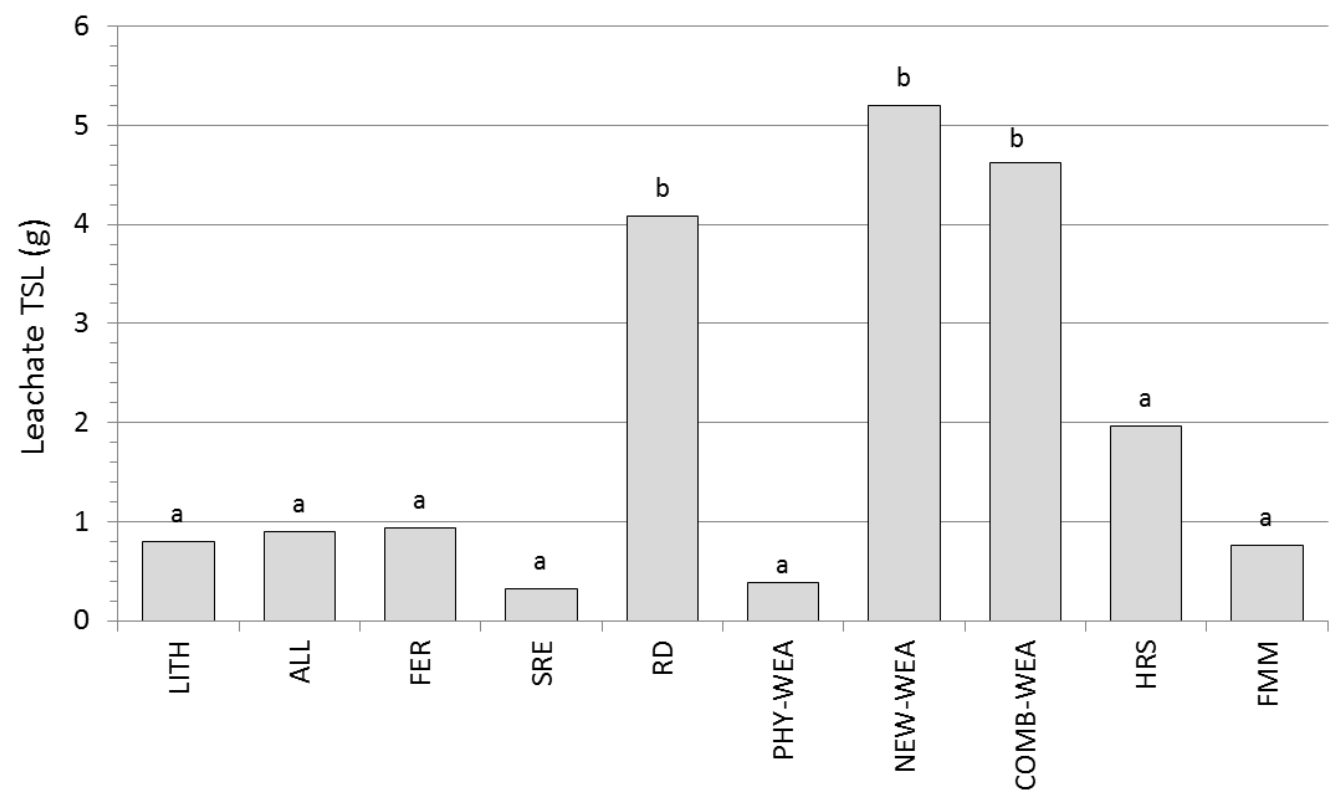

Slope Forming Material (SFM)

Figure 3 SFM leachate TSL (g); note: bars associated with the same letter are not significantly different at $\mathrm{p}<0.05$ as determined by One-way ANOVA and post-hoc Fisher LSD analysis

\subsubsection{Relative importance of physical and chemical properties on the hydrological response and comparative erodibility of soil SFMs}

The PCA results indicate significant divisions in the physical and chemical properties of the soil and non-soil SFMs. Consequently, the soil and non-soil physical and chemical properties are input as statistically independent data sets in the MRA analysis. 
For the soils (ALL, FER, LITH and SRE), the MRA results indicate that magnetic susceptibility (+ $\beta$ ) and DAD $53-63 \mu \mathrm{m}$ size fraction $(-\beta)$ accounted for over $96 \%$ of the observed variability in runoff volume (adjusted $R^{2}$ $=0.968$ ). Magnetic susceptibility (MS) alone accounted for over $85 \%$ (adjusted $R^{2}=0.854$ ) of the observed variability in runoff volume, with increasing MS resulting in a concomitant increase in runoff. Soil SRE is associated with significantly higher MS and runoff volume compared with the other soils (Table 1). Dearing (1999) suggested that iron ( $\mathrm{Fe}$ ) compounds have contrasting effects on soil erodibility as influenced by the path to formation of the Fe oxide/hydroxide, size of the Fe oxide crystal, soil pH, ionic composition of the soil solution and the presence of organic molecules (Duiker et al., 2003). Further, Rhoton et al. (1998) and Figueiredo et al. (1999) suggest that Fe compounds existing as discrete particles in soils can have a dispersive rather than a flocculating effect on soil aggregates. Although the results of the current study suggest a strong association between MS and runoff volume, this association is not transferred to the runoff TSL data, which is used as an indicator of erodibility. Further research is required to clarify the effect of MS on runoff volume.

With regards leachate, the MRA suggested that organic carbon $(+\beta)$, DAD $5.6-19 \mathrm{~mm}$ size fraction $(+\beta)$, coarse sand content $(-\beta)$, clay content $(+\beta)$ and bulk density $(-\beta)$ were significantly $(p>0.05)$ related to leachate volume accounting for over $95 \%$ of the observed variance in leachate (adjusted $R_{2}=0.953$ ). Further, soil organic carbon accounted for $86 \%$ of the observed variance in leachate volume (adjusted $R_{2}=$ 0.862 ), with increasing organic carbon and clay content being associated with increasing leachate volume. This is intuitive, as organic carbon and clay content are known have a direct impact on aggregate stability (Boix-Fayos et al., 2001), resulting in a limited supply of disaggregated material at the soil surface and thus restricting the blocking of pores at the immediate soil surface and maintaining infiltration. The positive influence of the DAD 5.6-19 mm size fraction and negative influence of bulk density on leachate volume are attributed to maintaining macro-porosity.

The MRA results indicate that clay content $(+\beta)$ and DAD 53-63 $\mu \mathrm{m}$ size fraction $(-\beta)$ account for over $93 \%$ of the observed variability in runoff TSL (adjusted $\left.R^{2}=0.934\right)$. Clay content $(\% \mathrm{w} / \mathrm{w})$ accounts for over $84 \%$ of the variability in runoff TSL (adjusted $R^{2}=0.842$ ), with increasing clay content being associated with a significant $(p<0.05)$ reduction in runoff TSL. Soils FER, LITH and ALL had significantly higher clay content compared with SRE and were associated with significantly lower soil runoff TSL values (Tables 1 and 3 ). The observed relationship between runoff TSL and clay content is again intuitive, as clays are known to improve particle cohesion and aggregate stability, particularly in sandy soils, resulting in low erodibility (Rhoton et al., 1998; Landon, 1991).

The DAD 53-63 $\mu \mathrm{m}$ size fraction is shown in the MRA to have a negative effect on both soil runoff TSL and runoff volume at $A D_{\text {amc }}$. However, for LITH, ALL, FER and SRE, the DAD 53-63 $\mu \mathrm{m}$ size fraction accounts for only $1.46,0.37,0.23$ and $1.84 \% \mathrm{w} / \mathrm{w}$ of the $\mathrm{DAD}$, respectively with significant differences in the order $\mathrm{LITH}=$ SRE $>A L L=F E R$. This suggests a statistical association rather than a process-based significant relationship.

\subsubsection{Relative importance of physical and chemical properties on the hydrological response and comparative erodibility of non-soil SFMs}

For the non-soils (RD, PHY-WEA, COMB-WEA, NEW-WEA, HRS and FMM), the MRA results indicate that the DAD $250-500 \mu \mathrm{m}(+\beta)$, DAD $<53 \mu \mathrm{m}(-\beta)$, DAD $63-125 \mu \mathrm{m}$ size fractions $(+\beta), \mathrm{pH}(-\beta)$, DAD $53-63 \mu \mathrm{m}$ size fraction $(+\beta)$, coarse sand content $(+\beta)$ and MS $(-\beta)$ combined account for over $88 \%$ of the variance in nonsoil runoff volume (adjusted $R^{2}=0.885$ ). The DAD $250-500 \mu \mathrm{m}$ size fraction accounted for $39.2 \%$ (adjusted $R^{2}=0.392$ ) of the observed variation in runoff volume, with the addition of the DAD 53-63 $\mu \mathrm{m}$ size fraction in the MRA accounting for further 15.4\%. PHY-WEA and HRS generated significantly higher runoff volumes compared with all other non-soil SFMs and were associated with significantly higher proportions of DAD 250-500 $\mu \mathrm{m}$ and DAD 63-125 $\mu \mathrm{m}$ size fractions. These results are in line with the findings of Loch and Rosewell (1992), Loch (1994) and Loch and Foley (1994), who observed that surface seal development was influenced by the proportion of fine materials at the surface, particularly the amount $<100 \mu \mathrm{m}$, which in 
combination with $<30 \mu \mathrm{m}$ sized particles can cause blockages within the surface matrix and promote the generation of runoff.

With regards the observed non-soil leachate results (Table 3), the MRA suggests that DAD 2.36-5.6 mm $(+\beta), \operatorname{DAD}<53 \mu \mathrm{m}(+\beta), \mathrm{pH}(+\beta), \mathrm{DAD} 53-63 \mu \mathrm{m}(-\beta)$, Quartz $(-\beta)$, Exch-Ca $(-\beta)$ and MS $(+\beta)$ were significantly related to leachate volume. The DAD $2.36-5.6 \mathrm{~mm}$ size fraction accounted for over $60 \%$ of the variance in leachate volume (adjusted $R^{2}=0.607$ ). DAD $2.36-5.6 \mathrm{~mm}$ sized aggregates are considered important for leachate generation, as their distribution will affect surface permeability. RD and COMB-WEA are associated with significantly higher proportions of DAD $2.36-5.6 \mathrm{~mm}$ aggregates compared with all other non-soil SFMs, at 19.9 and $17.7 \% \mathrm{w} / \mathrm{w}$ respectively, and are also associated with significantly high leachate volumes. However, the inclusion of the DAD 2.36-5.6 mm size fraction in the MRA masks highly significant differences in the \% $(\mathrm{w} / \mathrm{w})$ of DAD 5.6-19.0 $\mathrm{mm}$ size fractions between $\mathrm{RD}=\mathrm{COMB}-\mathrm{WEA}=\mathrm{NEW}$ WEA $=$ FMM $>$ HRS=PHY-WEA, with values of 29.1, 29.9, 35.3, 26.8, 19.9 and $17.7 \% \mathrm{w} / \mathrm{w}$ respectively. HRS and PHY-WEA are associated with significantly lower leachate volumes compared with the other non-soil SFMs. This infers that the DAD 5.6-19.0 mm size fraction has a significant influence on macro-porosity and the free movement of leachate through the non-soil SFMs. Hydraulic behaviour of SFMs is considered to be largely controlled by the connectivity between coarser fragments and by the amounts and mobility of smaller and primary particles (Hawkins, 1998; Fala et al., 2003; Smith et al., 1995), which block pores. The suggested influence of DAD $<53 \mu \mathrm{m}, \mathrm{pH}, \mathrm{DAD} 53-63 \mu \mathrm{m}$, Quartz, Exch-Ca and MS on non-soil leachate volume highlights the need for caution when undertaking MRA, such that statistical associations are clearly distinguished from robust and process-based relationships between dependant and independent variables.

With regards to non-soil runoff TSL, the MRA results indicate that kaolinite content $(+\beta)$, Exch-Mg $(-\beta)$ DAD $125-150 \mu \mathrm{m}$ size fraction $(-\beta)$ and coarse sand content $(+\beta)$ combined account for over $96 \%$ of the variability in runoff TSL (adjusted $\left.R^{2}=0.969\right)$. Kaolinite $(\% \mathrm{w} / \mathrm{w}$ ) alone accounts for over $85 \%$ of the variability in runoff TSL (adjusted $R^{2}=0.859$ ), with increasing kaolinite content being associated with a significant $(p<0.05)$ increase in runoff TSL. It is of note that the mineralogy of PHY-WEA is dominated by muscovite $(58 \% \mathrm{w} / \mathrm{w})$ rather than kaolinite $(19.2 \% \mathrm{w} / \mathrm{w})$. All other non-soil SFMs are associated with $<5.5 \%$ $\mathrm{w} / \mathrm{w}$ kaolinite and $0.0 \% \mathrm{w} / \mathrm{w}$ muscovite (Table 2). Further, the PSD of PHY-WEA is dominated by the siltsized fraction $(65.6 \% \mathrm{w} / \mathrm{w})$ compared with $<26.3 \%$ silt for all other non-soil SFMs (Table 3 ). The low CEC (2.43 meq $100 \mathrm{~g}^{-1}$ ) and absence of cementing cations predisposes PHY-WEA to rapid dispersion under rainfall.

Non-soil leachate MRA results are inconclusive and suggest counterintuitive associations between coarse sand content $(+\beta)$, quartz $(-\beta), \mathrm{pH}(+\beta)$, rutile $(-\beta)$, Exch-Ca $(+\beta)$, organic carbon $(-\beta)$, DAD $125-150 \mu \mathrm{m}(-\beta)$ and clay content $(+\beta)$. Coarse sand content accounts for over $40 \%$ of the variance in leachate TSL. However, further research is necessary to fully understand factors affecting leachate TSL in non-soil SFMs.

\section{$4 \quad$ Conclusions}

The results show that the hydrological response of soils LITH, ALL and FER is the generation of leachate, with runoff and leachate values of 617,143 and $267 \mathrm{ml}$ and of 3,884, 5,888 and 5,456 ml, respectively. A similar trend is observed for non-soils RD, NEW-WEA, COMB-WEA and FMM. In contrast, the hydrological response of PHY-WEA and HRS is the preferential generation of runoff. The high runoff and runoff TSL associated with PHY-WEA, coupled with the expected volume of material to be generated throughout the 'life of mine' (circa 300 million $\mathrm{m}^{3}$ ), pose a significant risk to mining operations and dominate the design of waste rock stockpiles and erosion control management measures. The erodibility and hydrological response of PHY-WEA is largely due to a 'perfect storm' of physical and chemical properties - namely, a comparatively high proportion of fine (250-500 $\mu \mathrm{m}$ and 63-125 $\mu \mathrm{m})$ DAD-size fractions, a low CEC and the absence of cementing cations ( $\mathrm{Ca}, \mathrm{Mg}$ and $\mathrm{K}$ ), mineralogy dominated by muscovite and PSD dominated by easily entrained and readily transported silt-sized particles. These combine to promote the dispersion of PHY-WEA by raindrop impacts, rapid sealing at the material surface (and associated armouring) and runoff generation, which in turn facilitates the entrainment of dispersed silt-sized muscovite particles and off-site transport. 
This research demonstrates the importance of pre-emptive and controlled erodibility studies to both quantify and understand the hydrological response of SFMs to design storm events as a prerequisite to the informed design of erosion and sediment control strategies that will be appropriate throughout the "life of mine'. In addition, the current research highlights the need to quantify the hydrological response and erodibility of slope-forming materials derived from mine sites in the context of the entire erosion process, namely detachment (including seal formation), entrainment and transport through surface runoff and/or via leachate and deposition.

\section{Acknowledgements}

The authors would like to thank Rio Tinto Iron Ore Atlantic for their financial support as well as the patience, collegiality and technical inputs/advice provided by Lucas Kitchen and Dan Eason during the course of this project. The authors are also grateful to Richard Andrews and his team at the Cranfield University Soils Laboratory and Rob Read at the Cranfield University Soil Erosion Laboratory - again, for their patience and support.

\section{References}

Andres, P. and Jorba, M. (2000) Mitigation strategies in some motorway embankments (Catalonia, Spain), Restoration Ecology, Vol. 8, pp. 268-275.

Boix-Fayos, C., Calvo-Cases, A., Imeson, A.C. and Soriano-Soto, M.D. (2001) Influence of soil properties on the aggregation of some Mediterranean soils and the use of aggregate size and stability as land degradation indicators, Catena, Vol. 44, pp. 47-67.

BSI (British Standards Institution) (2010) BS ISO 11277:2009, Soil quality: determination of particle size distribution in mineral soil material, method by sieving and sedimentation, London.

Dearing, J. (1999) Magnetic susceptibility, in Environmental Magnetism: A Practical Guide, J. Walden, F. Oldfield and J. Smith (eds), Quaternary Research Association, London.

Duiker, S.W., Rhoton, F.E., Torrent, J., Smeck, N.E. and Lal, R. (2003) Iron hydro (oxides) crystallinity effects on soil aggregation, Soil Science Society of America, Vol. 67, pp. 606-611.

Fala, O., Aubertin, M., Molson, J., Busssiére, B., Wilson, G.W., Chapuis, R. and Martin, V. (2003) Numerical modelling of unsaturated flow in uniform and heterogeneous waste rock piles, in Proceedings 6th International Conference Acid Rock Drainage, 12-18 July, Cairns, Queensland, Australia.

Figueiredo, M.D.A., Augustin, C.H.R.R. and Fabris, J.D. (1999) Mineralogy, size, morphology and porosity of aggregates and their relationship with soil susceptibility to water erosion, Hyperfine Interactions, Vol. 122, pp. 174-184.

Hawkins, J.W. (1998) Hydrological characteristics of surface-mine spoil, in Coal Mine Drainage Prediction and Pollution Prevention in Pennsylvania, K.B.C. Brady, T. Kania, M.W. Smith and R.J. Hornberger (eds), Pennsylvania Department of Environmental Protection, Penn.

Lal, R. (1998) Drop-Size Distribution and Energy Load of Rainstorms at Ibadan, Western Nigeria, Soil and Tillage Research 48, pp. 103-114.

Landon, J.R. (1991) Booker Tropical Soil Manual, John Wiley and Sons, New York.

Loch. R.J. (1994) A method for measuring aggregate water stability for dryland soils with relevance to surface seal development, Australian Journal of Soil Research, Vol. 32, pp. 687-700.

Loch, R.J. (2000) Using rainfall simulation to guide planning and management of rehabilitated areas, Part 1: experimental methods and results from a study at the Northpakes mine, Australia, Land Degradation and Development, Vol. 11, pp. 221-240.

Loch, R.J. and Foley, J.L. (1994) Measurement of aggregate breakdown under rain: comparison with tests of water aggregate stability and rain relationships with field measurements and infiltration, Australian Journal of Soil Research, Vol. 32, pp. 701-720.

Loch, R.J. and Rosewell, C.J. (1992) Laboratory methods for measurements of soil erodibilities (K factors) for the universal soil loss equation, Australian Journal of Soil Research, Vol. 30, pp. 233-248.

MAFF (Ministry of Agriculture Fisheries and Food) (1986) Reference Book RB427: Analysis of Agricultural Materials, HSMO, London.

Moreno-de las Heras, M., Merino-Martin, L. and Nicolau, J.M. (2009) Effect of vegetation cover on the hydrology of reclaimed mining soils under Mediterranean-Continental climate, Catena, Vol. 77, pp. 39-47.

Nelson, D.W. and Sommers, L.E. (1996) Carbon and organic matter, in Methods of Soil Analysis, Part 3, Chemical Methods, D.L. Sparks (ed), Soil Science Society of America and American Society of Agronomy, Madison, Wisc., pp. 961-1,010.

Nimmo, J.R. and Perkins, K.S. (2002) Aggregate stability and size distribution, in Methods in Soil Analysis: Part 4, Physical Methods, D.H. Dane and G.C. Topp (eds), Soil Science Society of America, Madison, Wisc., pp. 317-328.

Omotoso, O., McCarty, D.K., Hillier, S. and Kleeberg, R. (2006) Some successful approaches to quantitative mineral analysis as revealed by the 3rd Reynolds Cup Contest, Clay and Minerals, Vol. 54, pp. 748-760.

Rhoades, J.D. (1996) Salinity, electrical conductivity and total dissolved solids, in Methods of Soil Analysis: Part 3, Chemical Methods, D.L. Sparks (ed), American Society of Agronomy, Madison, Wisc., pp. 417-435. 
Rhoton, F.E., Romkens, M.J.M. and Lindbo, D.L. (1998) Iron oxides - erodibility interactions for soils of the Memphis Catena, Soil Science Society of American Journal, Vol. 62, pp. 1,693-1,703.

Smith, K.A. and Mullins, C.E. (2006) Soil Environmental Analysis: Physical Methods, 2nd ed. rev. and expanded, Marcel Dekker Inc., New York.

Smith, L., Lopez, D.L., Beckie, R., Morin, K., Dawson, R. and Price, W. (1995) Hydrogeology of Waste Rock Drainage, Final Report to Department of Natural Resources Canada, pp. 1-111.

So, H.B, Yatapanage, K. and Horn, C.P. (2002) Mine erosion: an integrated erosion and landscape design package for monitoring and modelling erosion from steep hillslopes on mine spoils, 12th ISCO Conference, 26-31 May, Beijing, pp. 36-41.

Thomas, G.W. (1996) Soil pH and soil acidity, in Methods of Soil Analysis: Part 3, Chemical Methods, D.L. Sparks (ed), American Society of Agronomy, Madison, Wisc., pp. 475-490.

Williams, D.J. (2001) Prediction of erosion from steep mine waste slopes, Environmental Management and Health, Vol. 12, pp. 35-50. 